JMI Vol. 43 No. 2, Desember 2021

\title{
METAL INDONESIA
}

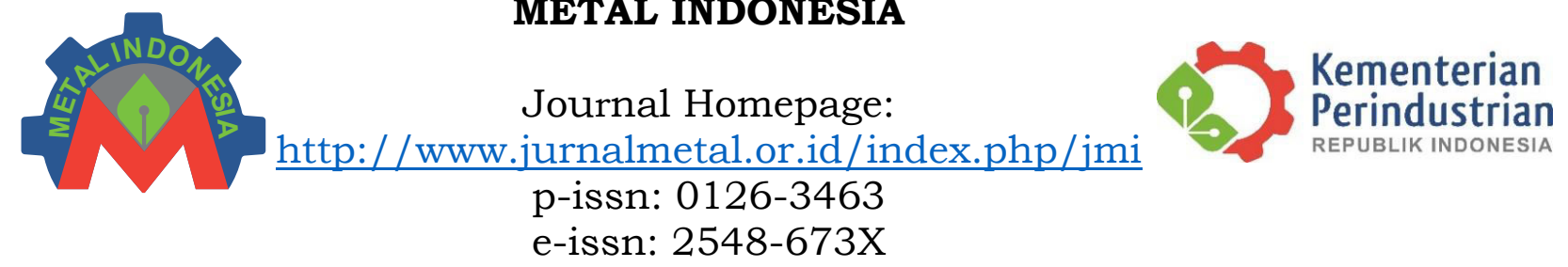
KARAKTERISASI SIFAT FISIK BENTONIT RIAU MELALUI METODE PENGUJIAN DISTRIBUSI UKURAN, SWELLING INDEX, PENGUKURAN pH, DAN METHYLENE BLUE VALUE

\section{CHARACTERIZATION OF BENTONIT PHYSICAL PROPERTIES ORIGINATING FROM RIAU THROUGH SIZE DISTRIBUTION TESTING, SWELLING INDEX, pH MEASUREMENT, AND METHYLENE BLUE VALUE}

\author{
Moch Iqbal Zaelana Muttahar ${ }^{1}$, Dagus Resmana Djuanda ${ }^{1}, \operatorname{Eva~Afrilinda~}^{1}$, Supriyadi $^{1}$ \\ ${ }^{1}$ Balai Besar Logam dan Mesin-Kementerian Perindustrian \\ Jl. Sangkuriang No. 12 - Bandung 40135, Jawa Barat, Indonesia \\ E-mail : mochiqbal@kemenperin.go.id
}

\begin{abstract}
Abstrak
Di alam terdapat beberapa jenis bentonite yang biasa digunakan dalam aplikasi kehidupan seharihari, salah satunya Natrium-Bentonit dan Kalsium-Bentonit. Kedua jenis bentonit tersebut memiliki karakteristik yang berbeda sehingga aplikasi penggunaannya pun berbeda. Karena perbedaan hal tersebut, maka penelitian ini berfokus pada proses karakterisasi bentonit yang berasal dari Riau. Pengamatan yang dilakukan berupa pengukuran distribusi ukuran bentonitit, pengamatan Swelling Index Bentonit, pengukuran $\mathrm{pH}$, dan pengukuran nilai Methylene Blue Value (MBV). Hasil penelitian menunjukkan bentonit Riau memiliki \%berat tertampung pada ayakan 100 mesh sebesar 20,1\% dan \%berat tertampung pada ayakan 200 mesh sebesar 16,2\% dengan nilai lolos sebanyak $80 \%$ (passing through 80\%/P80) sebesar 0,64 mm, kemudian didapatkan nilai kadar air sebesar 3,32\%. Sifat swelling index bentonit Riau sebesar $3 \mathrm{~mL} / 2 \mathrm{~g}$ sehingga termasuk bentonit dengan kategori bentonit non swelling. Bentonit Riau memiliki $\mathrm{pH}$ range sebesar 4-5. Hasil dari seluruh penelitian tersebut membuktikan bahwa bentonit yang diuji adalah bentonit dengan basis kalsium. Bentonit ini cocok diaplikasikan untuk industri kebutuhan sehari-hari, seperti bahan pada pembersih wajah, salep kulit, deterjen, dan penjernih minyak goreng.
\end{abstract}

Kata Kunci: Bentonit, swelling index, distribusi ukuran, $p H$.

\begin{abstract}
In nature, there are several types of bentonite that commonly used in daily life applications, one of which is Natrium-Bentonite and Calcium-Bentonite. The two types of bentonite have different characteristics so that their application is different. Due to these differences, this research focuses on the process of characterizing bentonite originating from Riau. Observations were made in the form of measuring the size distribution of bentonite, observing the Swelling Index of
\end{abstract}


bentonite, measuring $\mathrm{pH}$, and measuring the value of Methylene Blue Value (MBV). The results showed that Riau bentonite had a \%passing through 100Mesh of $20.1 \%$ and a \%passing through of 200Mesh of $16.2 \%$ with a passing through $80 \%$ (P80) value of $0.64 \mathrm{~mm}$, then the water content value was 3, 32\%. The swelling index of Riau bentonite is $3 \mathrm{~mL} / 2 \mathrm{~g}$, so it is classified as bentonite in the category of non-swelling bentonite. Riau bentonite has a $\mathrm{pH}$ range of 4-5. The results of all these studies prove that the bentonite tested in this research is calcium bentonite. This bentonite is suitable for use in the daily necessities industry, such as an ingredient in facial cleansers, skin ointments, detergents, and cooking oil purifiers.

Keywords : Bentonite, swelling index, size distribution, $\mathrm{pH}$.

\section{PENDAHULUAN}

Bentonit adalah istilah komersial untuk tanah liat yang terdiri dari montmorillonit dan mineral seperti kuarsa, kalsit, dolomit, dan feldspar. Nama montmorillonite ini berasal dari jenis lempung plastis yang ditemukan di Montmorillonite, Perancis pada tahun 1847 (Zaimahwati et al. 2018). Bentonit terbentuk dari hasil transformasi hidrotermal abu vulkanik yang sebagian besar merupakan mineral montmorillonit yang memiliki struktur lembaran. Mineral lain yang termasuk dalam montmorillonit adalah hectorite, saponite, beidellite dan nontronite. Montmorillonit adalah mineral yang terdiri dari struktur aluminium silikat terhidrasi tiga lapis, yaitu, dua lapisan serpihan silika tetrahedral dan satu lapisan serpihan alumina oktahedral (Fisli Mujinem; Sumardjo, Sumardjo 2008).

Terdapat dua jenis bentonit di alam, yaitu natrium bentonit dan kalsium bentonit. Natrium bentonit mengandung lebih banyak ion $\mathrm{Na}^{+}$daripada ion $\mathrm{Ca}^{2+}$ dan $\mathrm{Mg}^{2+}$. Ketika direndam dalam air, bentonit ini dapat menyerap air dan mengembang antara 8-15 kali dan tetap terdispersi dalam air untuk jangka waktu tertentu. Sifat khusus dari bentonit adalah kemampuan untuk membentuk gel thixotrophic dengan air. Kemampuan untuk menyerap air dalam jumlah besar dan kapasitas tukar kation yang tinggi. Meskipun demikian, kalsium bentonit memiliki jumlah cadangan yang lebih besar dibandingkan dengan natrium bentonit.
Keunikan sifat bentonit yaitu dapat mengembang dan membentuk koloid jika dimasukkan kedalam air (Ridwan 2019). Perbedaan sifat tersebut menyebabkan perbedaan aplikasi di dunia industri, Nabentonite memiliki kegunaan sebagai pembilas lumpur dalam kegiatan pengeboran, pengikat pasir pada pengecoran logam, dan menyumbat kebocoran pada bendungan dan kolam. Ca-bentonit digunakan sebagai pengikat untuk pembuatan pelet bijih besi, pemurni pada industri kelapa sawit, farmasi, dan industry kebersihan lainnya. Daerah penghasil utama natrium bentonit di dunia adalah Wyoming, Montana dan South Dakota sedangkan Ca-bentonit ditemukan didaerah sekitarnya dengan cadangan yang lebih besar.

Cetakan pasir basah dalam proses pengecoran, menggunakan bentonit sebagai pengikat. Selama proses pengecoran, panas yang dipindahkan ke pasir di sekitar cetakan menyebabkan degradasi struktur bentonit, sehingga membentuk jenis endapan baru di permukaan butiran pasir. Pada proses pengecoran menggunakan cetakan pasir basah, sering ditemukan cacat yang tidak diinginkan pada produk hasil pengecoran seperti kekasaran permukaan coran, intrusi logam cair ke dalam cetakan, gelembung udara, rongga, kegagalan cetakan, dan inklusi terak. Pembentukan cacat ini dipengaruhi oleh fluiditas (permeabilitas) dan stabilitas dimensi yang buruk dari gas (Bahrudin, Harjanto, and Saputro 2020). Ini mungkin karena campuran pengikat pasir basah yang 
tidak mencukupi atau terlalu tinggi atau jenis pengikat itu sendiri yang belum mampu menunjang daya ikat antar pasir pada cetakan basah. Pengikat dalam hal ini adalah bentonit. Karena campuran pengikat dapat mengubah sifat-sifat campuran pasir cetakan, pengaturan campuran pengikat dengan isi pasir cetakan, terutama pasir cetakan basah, merupakan faktor yang sangat penting.

Kualitas bentonit yang digunakan merupakan salah satu penunjang baiknya cetakan pasir yang dibuat yang mana kualitas tersebut memainkan peran penting dalam mencapai kualitas coran yang baik. Dalam penelitian ini, sifat permeabilitas dan kekerasan cetakan difokuskan untuk meningkatkan kualitas cetakan. Sifat-sifat ini ditingkatkan dengan mengoptimalkan parameter persentase berat bentonit barat. Hasil menarik yang ditemukan pada penelitian Nandagopal yang menunjukkan bahwa paduan parameter variasi persen bentonit, kekerasan nominal cetakan dan pengurangan ketebalan dinding meningkatkan kualitas cetakan dengan meningkatkan nilai permeabilitas dari 80 menjadi 120 (Nandagopal 2020).

Karena perbedaan jenis bentonit dan kemampuan penyerapan air yang cukup signifikan ini menyebabkan perbedaan aplikasi dari bentonit, maka penelitian ini berfokus pada proses karakterisasi bentonit yang berasal dari riau melalui perhitungan distribusi ukuran bentonit, swelling index, $p H$ value, dan methylene blue value (MBV).

\section{METODOLOGI}

\section{Bahan dan Proses Penelitian}

Dalam proses karakterisasi bentonit ini bahan bentonit berasal dari Provinsi Riau Indonesia.

\section{Pengujian Distribusi Ukuran Bentonit}

Bahan bentonit dikeringkan sebelum disaring, dengan berat awal (kering) $10 \mathrm{~g}$ diperoleh melalui metode sampling coning quartering, setidaknya 5 saringan ukuran yang berbeda digunakan. Bagian bentonit $\left(\mathrm{f}_{\mathrm{n}}\right)$, yang melewati saringan ( $\mathrm{n}$ ) dihitung untuk setiap ukuran saringan dan hasilnya disajikan sebagai ukuran $\left(f_{n}\right)$ versus butiran pada grafik. Sampel bentonit diayak selana 10 menit menggunakan mesin shiever Shaker. Hasil perhitungan nilai distribusi ukuran bentonite ditunjukkan dengan nilai lolos ayakan 100\# dan 200\# (mesh), serta analisis perhitungan ditambahkan untuk memperkirakan nilai lolos sebanyak $80 \%$ (P80). Standar pengayakan mengikuti standar ISO 17892:2004.

\section{Pengamatan Swelling Index Bentonit}

Pengamatan swelling index dilakukan dengan pengayakan bentonit dengan ayakan ukuran 200 mesh, kemudian siapkan dua sampel dengan berat masing-masing $2 \mathrm{gr}$ dan dimasukkan kedalam gelas ukur berisi aquades sebanyak $90 \mathrm{ml}$ secara perlahan. Setelah semua bentonit masuk ke dalam air bentonit didiamkan dan diamati kembali setelah 24 jam perendaman mengikuti standar pengujian ASTM D 5890-06 .

\section{Pengukuran $\mathrm{pH}$ bentonit}

Pengukuran $\mathrm{pH}$ dilakukan dengan melarutkan bentonit seberat 0,5 gr dengan air sebanyak $100 \mathrm{ml}$ didalam breaker glass. Kemudian dilakukan pengukuran menggunakan lakmus universal dan $\mathrm{pH}$ meter. Pengujian ini mengikuti standar ASTM D 4972.

\section{Pengamatan Methylene Blue Value (MBV)}

Sampel bentonit dengan berat kering sebesar 0,5 gr dilarutkan dalam $50 \mathrm{ml}$ larutan Tetrasodium Phyroposhapte dengan konsentrasi volume 10\%. Pelarutan bentonit dilakukan pada temperatur $80 \mathrm{C}$ selama 10 menit kemudian didinginkan hingga temperatur kamar. Penambahan $\mathrm{H}_{2} \mathrm{SO}_{4}$ dilakukan sebanyak $10 \mathrm{ml}$, aduk selama 1 menit. Tritasi dengan Methylene Blue sesuai volume yang dibutuhkan sampai terbentuk 
halo pada kertas filter. Pengujian ini mengikuti standar ASTM C837.

\section{HASIL DAN PEMBAHASAN Distribusi Ukuran Bentonit}

Pada hasil pengukuran distribusi ukuran bentonit dengan proses pengayakan tersebut dihasilkanlah hasil uji \%passing through 100 mesh sebesar 20,1\%, dan \%passing through 200 mesh sebesar 16,2\%. Data hasil pengujian ditunjukkan pada Tabel 1 dengan nilai P80 yang didapatkan adalah sebesar 0,64 mm. Distribusi besar butir bentonit akan sangat mempengaruhi kualitas dari suatu produk, khususnya produk hasil proses pengecoran (Karimi and Salem 2011). Permukaan hasil pengecoran akan menjadi halus jika cetakan coran dibuat di dalam cetakan yang berbutir halus. Tetapi kalau butir pasir dan pengikatnya terlalu halus, gas yang ditimbulkan akan sulit keluar schingga membuat cacat pada hasil pengecoran yaitu berupa gelembung udara (Asti 2001). Grafik distribusi ukuran bentonit ditunjukkan pada Gambar 1.

Tabel 1. Data distribusi ukuran bentonit

\begin{tabular}{|l|c|c|c|c|}
\hline $\begin{array}{l}\text { Ukuran } \\
\text { Ayakan (mm) }\end{array}$ & \multicolumn{2}{l|}{$\begin{array}{l}\text { Berat } \\
\text { Kumulatif (gr) }\end{array}$} & \multicolumn{2}{l|}{$\begin{array}{l}\text { \%Brat } \\
\text { kumulatif } \\
(\%)\end{array}$} \\
\hline & 1 & 2 & 1 & 2 \\
\hline 0,71 & 1,25 & 1,32 & 12,7 & 13,3 \\
\hline 0,5 & 3,4 & 3,23 & 34,4 & 32,5 \\
\hline 0,25 & 6,42 & 6,32 & 65,0 & 63,6 \\
\hline 0,125 & 7,98 & 8,03 & 80,8 & 80,8 \\
\hline 0,063 & 8,39 & 8,37 & 84,9 & 84,2 \\
\hline PAN & 9,88 & 9,94 & 100,0 & 100,0 \\
\hline
\end{tabular}

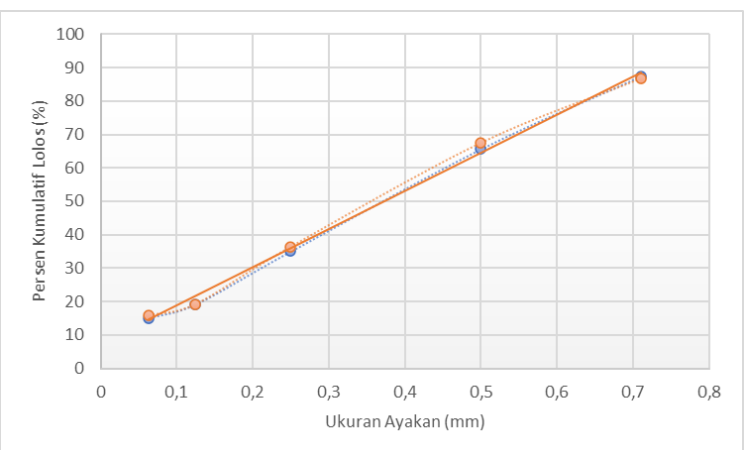

Gambar 1. Kurva hubungan ukuran ayakan dengan \%kumulatif lolos

\section{Swelling Index}

Kemampuan mengembang bentonit akibat berada dalam air adalah salah satu sifat yang paling penting dari bentonit karena beberapa aplikasi seperti aplikasi cairan pengeboran, dan untuk geoteknik dan lingkungan aplikasi rekayasa berada dalam lingkungan dengan kadar air yang cukup tinggi. Namun, pengembangan volume tanah terutama untuk tanah pondasi harus dikendalikan karena dapat menyebabkan masalah perekayasaan dikemudian hari, begitu pula bentonit yang akan diterapkan sebagai bahan pengikat pada campuran cetakan pasir basah, sangat dipengaruhi sekali oleh kemampuan pengembangan bentonit tersebut. Gambar 1 menunjukkan potensi swelling kalsium bentonit dengan metode persiapan dan pengujian sesuai dengan ASTM D5890. Sampel kering sebanyak $2 \mathrm{~g}$ dan dihaluskan bentonit tanah didispersikan ke dalam silinder $100 \mathrm{~mL}$ dengan penambahan $0,1 \mathrm{~g}$. Setiap kenaikan membutuhkan setidaknya 10 menit untuk memungkinkan hidrasi penuh dan penurunan bentonit. Bentonit yang diuji dalam penelitian ini memiliki nilai rata-rata swelling pada $3 \mathrm{~mL} / 2 \mathrm{~g}$. Namun, seperti dapat dilihat pada Gambar 2, indeks pembengkakan rata-rata untuk kalsium bentonit cukup rendah. Hal ini sejalan dengan penelitian Kiviranta yang menunjukkan nilai swelling index rata-rata kalsium bentonit kurang dari natrium bentonit. Hasil yang signifikan ini 
menunjukkan bahwa kandungan kation yang terdapat pada sampel bentonit yang berasal dari Riau mengandung $\mathrm{Ca}$ yang tinggi karena $\mathrm{Na}+$ yang tinggi meningkatkan swelling index sedangkan $\mathrm{Ca}+$ yang tinggi memiliki properti berupa nilai swelling yang rendah, selain itu jika kandungan $\mathrm{Mg} 2+$ tinggi ,ini akan mengurangi potensi swelling .

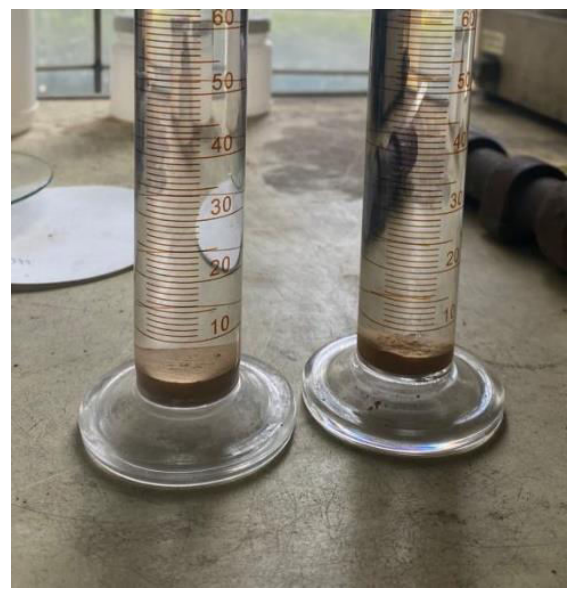

Gambar 2. Perendaman bentonit setelah 24 jam

\section{Pengukuran pH Bentonit}

Dari hasil pengujian didapatkan $\mathrm{pH}$ rata rata bentonit adalah sebesar 4-5, hal ini menunjukkan karakteristik bentonit jenis CaBentonit. Jenis ini mengandung kalsium $\left(\mathrm{Ca}_{2} \mathrm{O}\right)$ dan magnesium $(\mathrm{MgO})$ dengan kandungan yang lebih banyak dibandingkan dengan natrium. Temuan ini didukung oleh sifat penyerapan air yang minim pada pengamatan swelling index sehingga apabila didispersikan dalam air akan cepat mengendap (tidak membentuk suspensi) (Sirait 2018).

\section{Pengamatan Methylene Blue Value (MBV)}

Dari pengamatan $\mathrm{MBV}$, didapatkan bahwa halo muncul pada konsentrasi $\mathrm{H}_{2} \mathrm{SO}_{4}$ $5 \%$ sebanyak $50 \mathrm{ml}$. tingginya jumlah larutan yang diperlukan untuk dekolorasi (ditandai dengan terbentuknya halo) disebabkan oleh kualitas atau luas permukaan dari bentonit yang dihasilkan. Selain itu, $\mathrm{H}_{2} \mathrm{SO}_{4}$ mempengaruhi luas permukaan dari bentonit
, hal ini terjadi karena sifat $\mathrm{H}_{2} \mathrm{SO}_{4}$ yang mudah terionisasi dan bersifat reaktif terhadap ionion yang terdapat pada bentonit. Penambahan $\mathrm{H}_{2} \mathrm{SO}_{4}$ ini menyebabkan terjadinya pergantian ion $\mathrm{K}^{+}, \mathrm{Na}^{+}$, dan $\mathrm{Ca}^{++}$. Larutnya kation dan anion ini mengakibatkan pelepasan ion $\mathrm{Al}, \mathrm{Mg}$, $\mathrm{Fe}$, dan pengotorpengotor lainnya dari kisi kristal bentonit. Hal ini berimplikasi pada permukaan butiran bentonit menjadi lebih porous, lebih aktif dan luas permukaannya menjadi lebih besar serta sifat penyerapannya semakin bertambah besar. Semakin luas permukaan bentonit maka semakin banyak zat warrna biru metilena yang teradsorpsi yang menunjukkan semakin banyaknya kebutuhan untuk aktivasi bentonit (Naqiatuddin et al. 2014).

\section{KESIMPULAN}

Bentonit Riau yang telah diuji memiliki \%passing through 100Mesh sebesar 20,1\% dan \%passing through 200Mesh sebesar $16,2 \%$ dengan nilai P80 sebesar 0,64 mm, kemudian didapatkan nilai kadar air sebesar $3,32 \%$. Sifat swelling index bentonit Riau sebesar $3 \mathrm{~mL} / 2 \mathrm{~g}$ sehingga termasuk bentonit dengan kategori bentonit non swelling. Bentonit Riau memiliki pH range sebesar 45. Hasil dari seluruh penelitian tersebut membuktikan bahwa bentonit yang diuji adalah bentonit dengan basis kalsium, bentonit ini cocok diaplikasikan untuk industri kebutuhan sehari-hari, seperti bahan pada pembersih wajah, salep kulit, detergent, dan penjernih minyak goreng. Perbedaan sifat fisik dan kimia pada Na-Bentonit dan Ca-Bentonit menyebabkan aplikasi yang berbeda pula terutama di beberapa industri secara umum.

\section{DAFTAR PUSTAKA}

Asti, Murni. 2001. "Komposisi Pasir Cetak Untuk Pengecoran Logam.Pdf."

Bahrudin, Faqih, Budi Harjanto, and Herman Saputro. 2020. "Pengaruh Variasi Penambahan Fly Ash \& Bentonit Terhadap Sifat Pasir Cetak Dan Cacat 
Gasholes Pada Hasil Pengecoran Logam Aluminium" 8 (2): 53-61.

Fisli Mujinem; Sumardjo, Sumardjo, Adel; Mujinem. 2008. "Isolasi Dan Karakterisasi Montmorillonite Dari Bentonit Sukabumi (Indonesia)." Jurnal Sains Materi Indonesia 10 (Vol 10, No 1: OKTOBER 2008): 12-17. http://jurnal.batan.go.id/index.php/jsmi/ article/view/4572.

Karimi, L., and A. Salem. 2011. "The Role of Bentonite Particle Size Distribution on Kinetic of Cation Exchange Capacity." Journal of Industrial and Engineering Chemistry 17 (1): 90-95. https://doi.org/10.1016/j.jiec.2010.12.00 2.

Nandagopal, M. 2020. "Multi-Objective Optimization of Western Bentonite (A12H2Na2O13Si4)-Blended Green Sand Casting Process Parameters to Improve Mould Quality," no. 92. https://doi.org/https://doi.org/10.1139/tc sme-2020-0011.

Naqiatuddin, Nurul Alam, Jurusan Kimia, Fakultas Ma, and Ilmu Pengetahuan. 2014. "Chemical Activatio Ation of Bentonite Clay and Its Ads Adsorption Pro Roperties of Methylene Blue" 14 (2): 7-11.

Ridwan. 2019. "Pengolahan Dan Karaterisasi Bentonit Alam Aceh Sebagai Pengisi Bionanokomposit Poli Kaprolakton /Poli Asam Laktat/Kitosan (Pcl/Pla/Kitosan)." Disertasi Ilmu Kimia Fakultas Mtematika Dan Ilmu Pengetahuan Alam.

Sirait, Makmur. 2018. Polivinyl Alkohol Dan Campuran Bentonit.

Zaimahwati, Zaimahwati, Yuniati Yuniati, Ramzi Jalal, Syahman Zhafiri, and Yuli Yetri. 2018. "Isolasi Dan Karakterisasi Bentonit Alam Menjadi Nanopartikel Monmorillonit." Jurnal Katalisator 3 (1): 12.

https://doi.org/10.22216/jk.v3i1.2729. 